\title{
Effects of Pressure on Soot Parameters in an Ethane/Air Counterflow Diffusion Flame
}

\author{
Hafiz M. F. Amin, William L. Roberts \\ King Abdullah University of Science and Technology (KAUST) \\ Clean Combustion Research Center (CCRC) \\ Thuwal 23955-6900, Saudi Arabia \\ Hafiz.amin@kaust.edu.sa; William.roberts@kaust.edu.sa
}

\begin{abstract}
In this work, an ethane/air counterflow diffusion flame at elevated pressures has been investigated using light scattering and extinction technique. An ethane/air counterflow diffusion flame has been stabilized from 2 to 5 atm in a pressure vessel which can provide optical access up to $160^{\circ}$ in angular direction. Effects of pressure on soot parameters such as soot volume fraction $\left(f_{v}\right)$, particle diameter $\left(d_{p}\right)$ and particle number density $\left(n_{p}\right)$ have been investigated. The Rayleigh-Debye-Gans theory for Polydisperse Fractal Aggregates (RDG-PFA) has been used to determine the soot parameters from light scattering and extinction data. Global strain rate $(a)$ of $30 s^{-1}$ is maintained at all pressures by adjusting the inlet flows. Scattering measurements are performed at $135^{\circ}$. By combining the scattering data with extinction measurements soot volume fraction, mean particle diameter and particle number densities, along the centerline of the counterflow flame, are calculated. Values of fractal parameters such as fractal dimension and fractal prefactor, are taken from the literature for atmospheric flames and they are assumed constant at all pressures. It is found that the primary particle diameter and soot volume fraction increase with pressure while the number densities of primary particles decrease due to coalescence.
\end{abstract}

Keywords: laser diagnostics, primary particle diameter, high pressure, counterflow, laminar flame

\section{Introduction}

High operating pressure is desirable in gas turbines and diesel engines to reduce the volume of the combustion chamber. Elevated pressure levels improve thermodynamic efficiency of the combustion devices but soot formation is enhanced with pressure. Soot emissions from the exhaust of combustion systems pose serious risk to human health and they are also a major contributor to global warming. Soot morphology affects its transport properties and interaction with human respiratory system and also has important effects for its atmospheric life time. Therefore, it is necessary to understand soot morphology at conditions relevant to practical combustion systems in order to improve computational codes and to develop effective emission control strategies.

Soot particle size has been studied for many years in laboratory flames at atmospheric pressure, using intrusive and non-intrusive diagnostic [1-6]. Limited studies are available at elevated pressures in which effects of pressure on soot volume fraction and particle size have been studied [7-9]. Flower and Bowman studied an ethylene/air diffusion flame up to $10 \mathrm{~atm}$. Light extinction method was applied to study the soot volume fraction at different axial locations allowing to identify the soot formation and oxidation zones. They found that peak integrated soot volume fraction scaled with pressure as $P^{1.2 \pm 0.1}$. Thomson et al. [10] studied methane/air flames up to 4.0 MPa, in a newly developed high pressure diffusion flame apparatus, using spectral soot emissions (SSE) and line-of-sight attenuation (LOSA) technique. Maximum soot volume fraction increased with pressure to a power 2 for pressure 0.5 to $2 \mathrm{MPa}$ and 1.2 for 2.0 to $4.0 \mathrm{MPa}$. Particle diameter was also measured in the same experimental setup using laser induced incandescence and dramatic increase in particle size with pressure was observed [11]. Most of the high pressure flames focused on soot studies are coflow flames in which high pressure of $10 \mathrm{MPa}$ have been reached [12]. However, coflow flames have some problems at elevated pressures such as heat loss to the burner [12]. Moreover, they have two dimensional structure and thus complex flow pattern which makes it difficult to understand soot mechanisms.

Optical diagnostic techniques are preferable for combustion studies due to their non-perturbing nature. Light scattering and extinction techniques have been used by many researchers to retrieve soot parameters in diffusion flames at atmospheric pressure [5, 13-15]. Scattering measurements when combined with light extinction measurements, primary particle size $\left(d_{p}\right)$ 
and soot volume fractions can be inferred. In this work, we have applied light scattering and extinction technique to investigate the effects of pressure on soot parameters. An ethane/air counterflow diffusion flame has been stabilized up to 5 atm in a pressure vessel which can provide the access for optical diagnostics. Counterflow flames are relatively immune from buoyancy instabilities and this configuration allows controlling the residence time by controlling the strain rates. Measurements of the scattering signals at $135^{\circ}$ in conjunction with light extinction data enable retrieving mean primary particle diameter and soot volume fraction along the centerline of counterflow flame at different pressures.

\section{Experimental setup}

Experimental setup is described in detail in [16] and a schematic of the setup is shown in Fig. 1. Experimental setup consists of a pressure vessel in which the counterflow flame is contained in a pressurized environment. The pressure vessel has a bottom flange which closes the vessel and can be raised or lowered using a motorized mechanism. The fuel, air and inert supplies inside the pressure vessel are provided through the connectors attached to the bottom flange. On the top part of the pressure vessel a pressure gauge is connected while the exhaust line from the top is connected to an electronically controlled back pressure regulator. The pressure vessel has four quartz windows of curved shape which can provide optical access up to $160^{\circ}$ in angular direction. A rotary stage is resting on four vertical translation stages and these translation stages allow balancing the rotary stage in horizontal plane. Scattered light collection optics are mounted on the rotary stage which enables us to position them at desired angles.

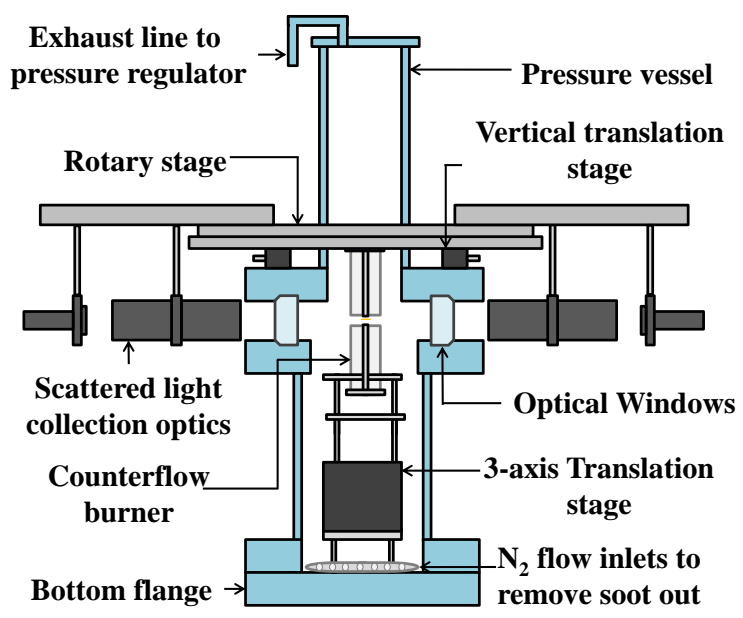

Fig. 1: Schematic of setup.

Counterflow burner has two opposed straight tubes of inside diameter of $8.1 \mathrm{~mm}$ for the mainstream flow. This dimension is chosen to minimize the total inlet flow rates at elevated pressures and to achieve the global strain rates $(a)$ comparable to the ones studied at atmospheric pressure. Air is provided from the top side while the ethane is supplied from the bottom side of the burner and the separation distance between the fuel and oxidizer tubes is $8.1 \mathrm{~mm}$. Global strain rate defined as the average velocity of air $\left(V_{\text {air }}\right)$ at the exit of the nozzle divided by half of the separation distance $(H)$ between the nozzles and $a=30 s^{-1}$ is maintained at all pressures while fuel and oxidizer streams have equal momentum. Fuel mole fraction is $X_{F}=1.0$ and the flame studied is soot formation flame, located on the oxidizer side of the stagnation plane. To prevent the entrainment, nitrogen curtain with the same velocity of the main sreams, is provided through coflow tubes of inside diameter of $28 \mathrm{~mm}$. The burner is mounted on xy-translation stages which allow aligning the center of the burner with laser beam. The xy-translation stages and the burner are attached on a vertical translation stage. To prevent the accumulation of soot on the optical windows, a flux of nitrogen gas flows around the optical windows without perturbing the flame and this nitrogen flow is provided through a circular ring attached on the bottom flange.

Fig. 2 shows the schematic of the optical arrangement for light scattering and extinction measurements. A vertically polarized laser beam, at a wavelength of $514.5 \mathrm{~nm}$, is emitted by an $\mathrm{Ar} / \mathrm{Kr}$ ion laser light source and is chopped at $1 \mathrm{kHz}$. The sending optics expand the laser beam which is then focused to a beam waist diameter of $0.1 \mathrm{~mm}$ at the center of the burner. The scattered light collection optics consist of a converging lens which collects the scattered light by the soot particles and focuses it to a pinhole which has a diameter of $0.15 \mathrm{~mm}$. Before the pinhole a polarizer is mounted to allow the 
measurements of only a vertically polarized light. Unwanted light from the surrounding and flame radiations are minimized by using a lock-in-amplifier and a bandpass filter in front of PMT.

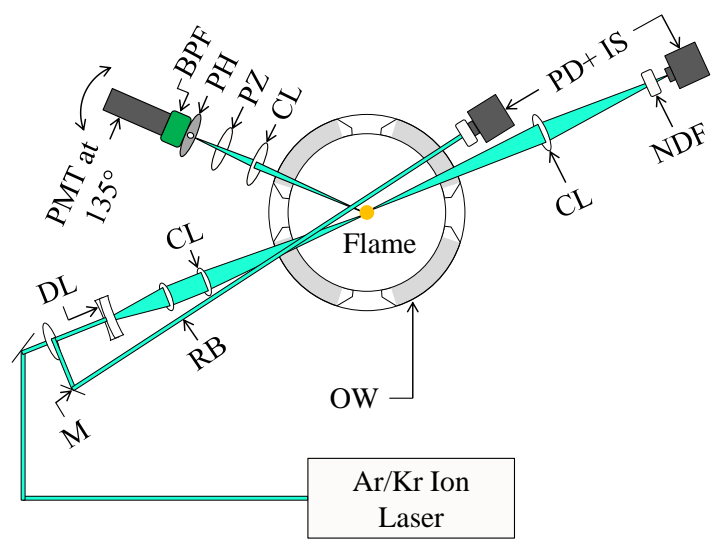

Fig. 2: Schematic of laser diagnostics: $\mathrm{M}=$ Mirror; $\mathrm{DL}=$ Diverging lens; $\mathrm{RB}=$ Reference beam; $\mathrm{CL}=$ Converging lens; $\mathrm{PZ}=$ Polarizer; $\mathrm{PH}=$ Pinhole; $\mathrm{BPF}=$ Bandpass filter; $\mathrm{PMT}=$ Photomultiplier tube; $\mathrm{PD}=$ Photodiode; $\mathrm{IS}=$ Integrating sphere; $\mathrm{NDF}=$ Neutral density filter; OW = Optical window.

The scattering intensity by soot particles, $I_{v v}{ }^{\text {soot}}$, is measured at particular location and the soot scattering coefficient, $K_{v v}{ }^{\text {soot }}$, at each location is calculated using the following

$$
K_{v v}^{s o o t}=K_{v v}^{c a l i b} \frac{I_{v v}^{s o o t}}{I_{v v}^{c a l i b}}
$$

Where, $I_{v v}{ }^{c a l i b}$, is the scattering intensity and $K_{v v}{ }^{c a l i b}$ is the known scattering coefficient of the calibration gas. Propane gas is used as a calibration gas. Scattering signal from the nitrogen gas is also measured and the noise from the internal reflections is calculated through the known ratio of the scattering coefficients of propane and nitrogen. Neutral density filters are used during the measurements of the scattering signal from soot particles due to several order of magnitude differences in the scattering intensities between the soot particles and the calibration gases. To ensure that the laser power reaching to the measurement volume in the flame is same as that of the calibration gases, correction of the incident and scattering light intensities is required. It is done by taking into account the attenuation of the laser signal from flame edge to the measurement location and from measurement location to the detector.

Light extinction is measured using the same sending optics. Transmitted laser beam, $I$, is focused on the integrating sphere using a biconvex lens. Integrating sphere is used to minimize the effects of beam steering. The incident, $I_{o}$, and the transmitted light intensities, $I$, are measured without and with the flame, respectively, by the photodiode detector mounted on the integrating sphere. From the ratio of the incident $\left(I_{o}\right)$ and transmitted $(I)$ light intensities, extinction coefficient can be calculated as

$$
K_{\text {ext }}=\frac{1}{S} \ln \left(\frac{I_{o}}{I}\right)
$$

Where $\mathrm{s}$ is the optical path length and it is measured by imaging the flame. A reference laser beam is also passed through the pressure vessel and the reference beam signal is measured to account for any change in laser power and optical transmissivity of optical windows due to soot accumulation, over time.

\section{Theoretical Methods}

Soot parameters are calculated following the detailed analysis of [2] based on the Rayleigh-Debye-Gans theory for fractal aggregates of small spherical particles. The soot volume fraction can be calculated from the extinction measurements as 


$$
f_{v}=\frac{\lambda}{6 \pi E} \frac{K_{\text {ext }}}{1+\rho_{s a}}
$$

Here, $\lambda$ is the wavelength used, $\mathrm{E}=\operatorname{Im}\left[\left(m^{2}-1\right) /\left(m^{2}+2\right)\right], m$ is the complex refractive index of soot and $\rho_{\mathrm{sa}}$ is the scattering to extinction ratio. The variation in the value of complex refractive index of soot is not known as a function of pressure and $m=1.62+0.66 i$ reported by [17] is chosen at all pressures. This value is reported for the same wavelength used in this experimental study and is shown to be independent of fuel type within the experimental uncertainties. The value of $E$, with experimental uncertainties corresponding to the chosen value of complex refractive index is $0.29 \pm 27 \%$ [17]. The ratio of the total scattering to extinction ratio is not constant and depends on the flame conditions as it changes with the particle diameter and aggregate size. Considering the results of [18] at atmospheric pressure, in which $\rho_{\mathrm{sa}}$ is found to change between 0.036 to 0.11 for the wavelength used in the present study, the value of $\rho_{\mathrm{sa}}$ is assumed to be 0.1 for all the flame conditions with $100 \%$ uncertainty. The primary particle diameter can be calculated by measuring the large angle scattering to absorption ratio. Therefore, scattering is measured at $135^{\circ}$ and primary particle diameter is calculated from the scattering to extinction ratio using the following relation

$$
d_{p}=\frac{\lambda}{\pi}\left[4 \pi \frac{E}{F} \frac{K_{v v}\left(\theta_{L}\right)}{K_{a b s}} \frac{\left(2 \sin \theta_{L} / 2\right)^{D_{f}}}{k_{f}}\right]^{1 /\left(3-D_{f}\right)}
$$

Here, $K_{a b s}$ is the absorption coefficient and is equal to $K_{\text {ext }}$ times $\left(1+\rho_{\mathrm{sa}}\right)^{-1} . F(m)=\left|\left(m^{2}-1\right) /\left(m^{2}+2\right)\right|^{2}, k_{f}$ is the fractal prefactor and $D_{f}$ is the fractal dimension. The value of $F$ with the reported uncertainties for the chosen value of complex refractive index is $0.27 \pm 44 \%$ [17]. $D_{f}=1.8$ and $k_{f}=2.2$ is employed for the present analysis as these values are shown to be representing the morphology of flame generated aggregates in a wide range of combustion conditions [19]. Once the soot volume fraction and primary particle size are known, particle number density is calculated using $n_{p}=\left(6 \times f_{v}\right) /\left(\pi \times d_{p}{ }^{3}\right)$.

\section{Results and discussions}

Soot volume fraction profiles measured in the axial direction along centerline of the counterflow flame are shown in Fig. 3. Error bars show the uncertainty contribution due to detector's response, absorption length, $\rho_{\mathrm{sa}}$ and refractive index function, $E$. An uncertainty of $10 \%$ is present in the measurements of absorption length which increases close to stagnation plane. Pure ethane/air flame is a soot formation flame and the sooting zones are located on the oxidizer side of the stagnation plane. Soot is produced on the fuel side of the flame and soot volume fraction increases as soot particles move towards the stagnation plane where they leak out. Soot volume fraction significantly increases with pressure and the stagnation plane shifts away from the fuel nozzle when the pressure is raised which shows the soot zone thickness decreases with pressure.

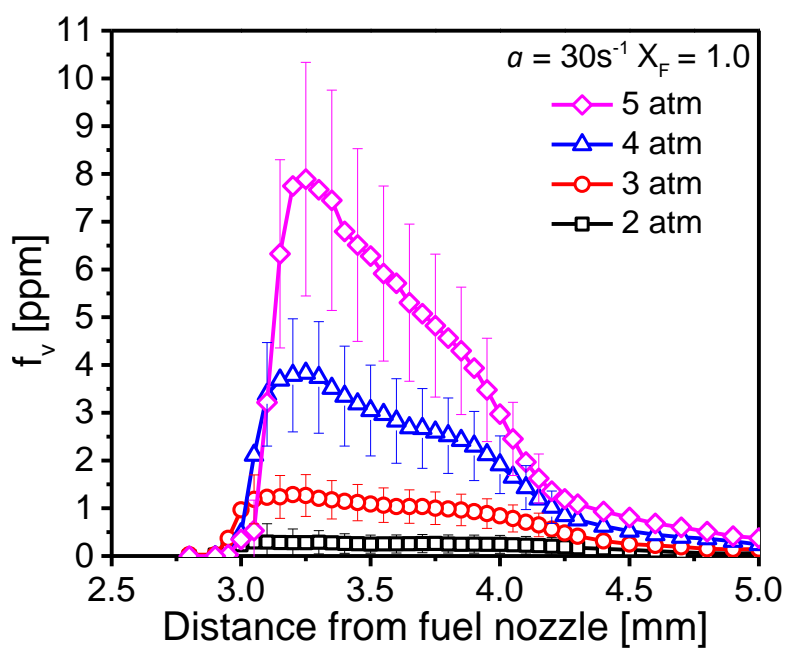

Fig. 3: Soot volume fraction profiles versus the distance from fuel nozzle. 
Axial profiles of scattering coefficients measured at $135^{\circ}$ along the centerline of the flame are shown in Fig. 4. Scattering coefficients start to increase at a distance of around $4 \mathrm{~mm}$ from the fuel nozzle and keep on increasing as the particles move towards the stagnation plane. Significant difference can be seen in the scattering coefficient profiles at different pressures because the scattering coefficients increase due to increase in soot volume fraction and particle size.

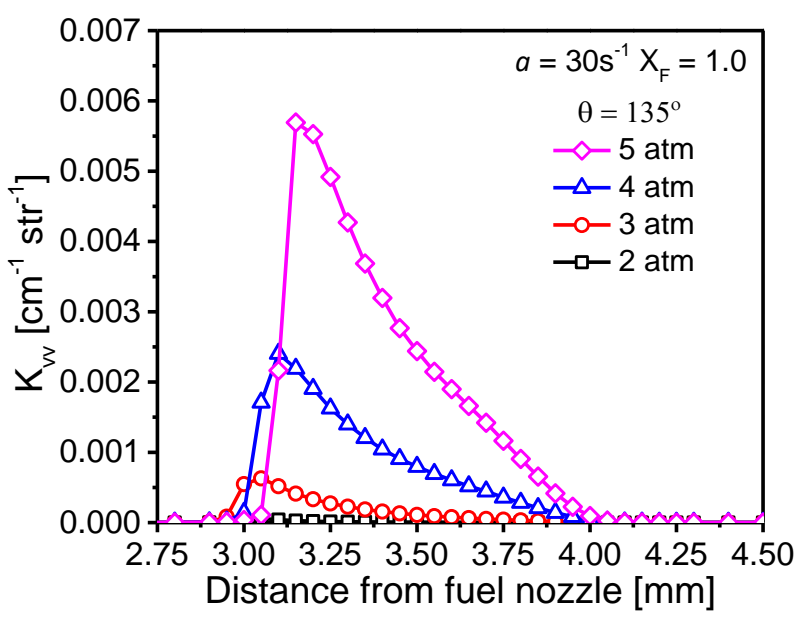

Fig. 4: Measured scattering coefficients versus the distance from fuel nozzle.

Fig. 5 shows the variation of the mean primary particle diameter measured along the centerline of the counterflow flame at various pressures. Major sources of uncertainties are absorption coefficient, $E, F$ and scattering coefficient. Uncertainty contribution of $K_{a b s}$, increases near the stagnation plane due to large uncertainty contribution by absorption length. Soot particles begin to form near the fuel side of the flame and they grow as they move along the flow field towards the stagnation plane. No oxidation is present in this soot formation flame. Therefore, particle diameters reach to their maximum values near the stagnation plane where they are convected away. Mean particle diameter also increases with pressure. The increase in particle size with pressure can be due to increased surface growth and coalescence.

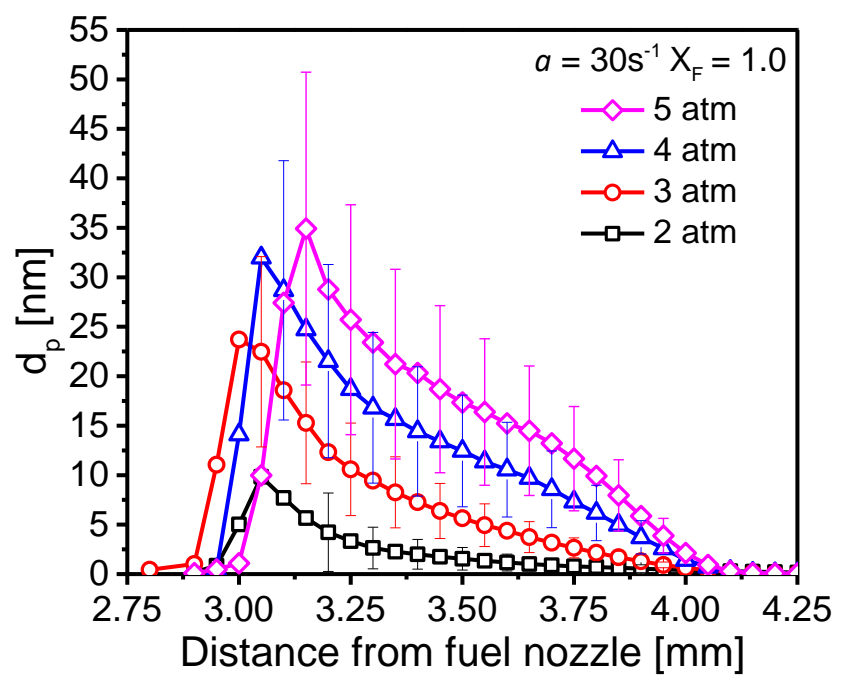

Fig. 5: Profiles of soot particle diameter versus the distance from fuel nozzle.

Number densities of primary particles as a function of the distance from fuel nozzle are shown in Fig. 6. At each pressure, particle number densities are high near the soot inception zone due to the nucleation process and they start to decrease while moving away from this zone towards the stagnation plane. The particle number densities decrease rapidly in the direction of particle transport but the particle size, as shown in Fig. 5, increases as the particles are convected towards stagnation plane. This behaviour shows that the number densities decrease in the direction of particle transport due to 
coalescence. At each axial location along the centerline of the flame the number densities of the primary particles decrease due to increased coalescence with pressure.

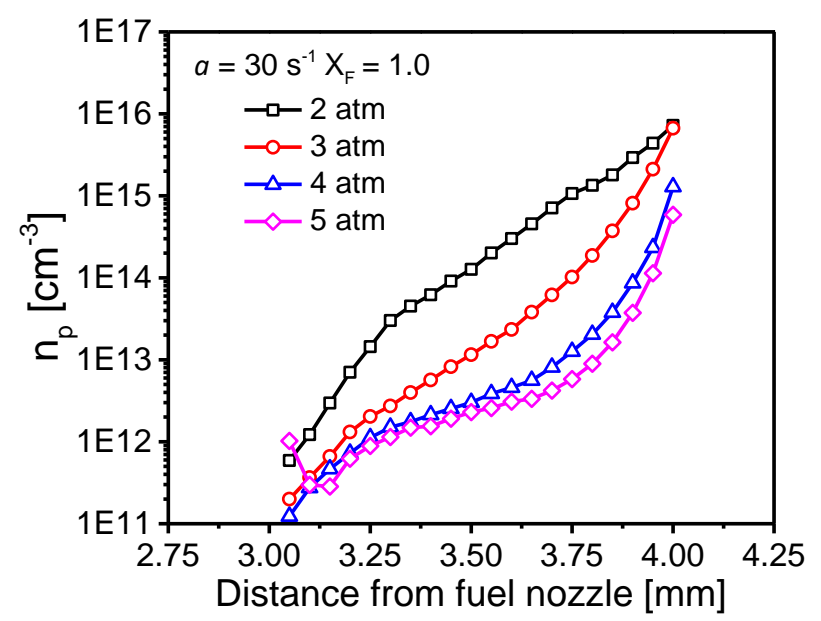

Fig. 6: Profiles of number density of particles versus the distance from fuel nozzle

\section{Conclusion}

Effects of pressure on soot concentration and particle diameter are studied in an ethane/air counterflow diffusion flame. From the light scattering and extinction measurements mean particle diameter, soot volume fraction and particle number densities are calculated, using RDG theory for fractal aggregates. Location of the stagnation plane shifts towards the flame and the soot zone thickness is found to decrease with pressure. Integrated soot volume fraction and peak soot volume fraction both increase with pressure. Increase in pressure results in increase in coalescence due to which mean primary particle diameter increases while the number densities of primary particles decrease at each axial location as the pressure increases from 2 to $5 \mathrm{~atm}$. The present investigation focuses non-premixed sooting flame at elevated pressures which is relevant to practical combustion systems. Experimental data generated on the influence of pressure on soot parameters is helpful in improving computational soot predictions under high pressure conditions.

\section{Acknowledgements}

The publication is based upon the work supported by King Abdullah University of Science and Technology (KAUST) Office of Sponsored Research (OSR) under Award no. 1402. The authors also thank Mr. Scott A. Steinmetz for his assistance.

\section{References}

[1] C. M. Sorensen, J. Cai, and N. Lu, "Light-scattering measurements of monomer size, monomers per aggregate, and fractal dimension for soot aggregates in flames," Appl Opt., vol. 31, pp. 6547-6557, 1992.

[2] U. O. Koylu, "Quantitative analysis of in situ optical diagnostics for inferring particle/aggregate parameters in flames: Implications for soot surface growth and total emissivity," Combust. Flame, vol. 109, pp. 488-500, 1997.

[3] B. Hu, B. Yang, and U. O. Koylu, "Soot measurements at the axis of an ethylene/air non-premixed turbulent jet flame," Combust. flame, vol. 134, pp. 93-106, 2003.

[4] T. C. Fang, C. M. Megaridis, W. A. Sowa, and G. S. Samuelsen, "Soot morphology in a liquid-fueled, swirl-stabilized combustor," Combust. flame, vol. 112, pp. 312-328, 1998.

[5] S. De Iuliis, F. Cignoli, S. Benecchi, and G. Zizak, "Determination of soot parameters by a two-angle scatteringextinction technique in an ethylene diffusion flame," Appl. Opt., vol. 37, pp. 7865-7874, 1998.

[6] S. De Iuliis, S. Maffi, F. Cignoli, and G. Zizak, "Three-angle scattering/extinction versus TEM measurements on soot in premixed ethylene/air flame," Appl. Phys. B, vol. 102, pp. 891-903, 2011.

[7] W. L. Flower and C. T. Bowman, "Soot production in axisymmetric laminar diffusion flames at pressures from one to ten atmospheres," Proc. Combust. Inst., vol. 21, pp. 1 I 15-1124, 1986.

[8] W. L. Flower, C. T.Bowman, "Measurements of the structure of sooting laminar diffusion flames at elevated pressures," Proc. Combust. Inst., vol. 20, pp. 1035-1044, 1985. 
[9] L. L. McCrain and W. L. Roberts, "Measurements of the soot volume field in laminar diffusion flames at elevated pressures," Combust. Flame, vol. 140, pp. 60-69, 2005.

[10] K. A. Thomson, O. L. Gulder, E. J. Weckman, R. A. Fraser, G. J. Smallwood, and D. R. Snelling, "Soot concentration and temperature measurements in co-annular, nonpremixed CH/air laminar flames at pressures up to $4 \mathrm{MPa}$," Combust. Flame, vol. 140, pp. 222-232, 2005.

[11] K. A. Thomson, D. R. Snelling, G. J. Smallwood, and F. Liu, "Laser induced incandescence measurements of soot volume fraction and effective particle size in a laminar co-annular non-premixed methane/air flame at pressures between 0.5-4.0 MPa," Appl. Phys. B, vol. 83, pp. 469-475, 2006.

[12] H. I. Joo and Ö. L. Gülder, "Soot formation and temperature structure in small methane-oxygen diffusion flames at subcritical and supercritical pressures," Combust. Flame, vol. 157, pp. 1194-1201, 2010.

[13] S. De Iuliis, F. Cignoli, S. Benecchi, and G. Zizak, "Investigation of the similarity of soot parameters in ethylene diffusion flames with different heights by extinction/scattering technique," in Proc. Combust. Inst., vol. 27, pp. 1549$1555,1998$.

[14] B. Yang and U. O. Koylu, "Soot processes in a strongly radiating turbulent flame from laser scattering/extinction experiments," J. Quant. Spectros. Radiat. Transfer, vol. 93, pp. 289-299, 2005.

[15] Bo Yang and U. O. Koylu, "Detailed soot field in a turbulent non-premixed ethylene/air flame from laser scattering and extinction experiments," Combust. Flame, vol. 141, pp. 55-65, 2005.

[16] H. M. F. Amin and W.L. Roberts, "Soot measurements by two angle scattering and extinction in an $\mathrm{N}_{2}$-diluted ethylene/air counterflow diffusion flame from 2 to 5 atm," in Proc. Combust. Inst., 36th International Symposium On Combustion, Seoul, Korea, vol. 36, 2016 (Submitted).

[17] S. S. Krishnan, K.-C. Lin, and G. M. Faeth, "Optical properties in the visible of overfire soot in large buoyant turbulent diffusion flames," J. Heat Transfer, vol. 122, pp. 517-524, 2000.

[18] F. Migliorini, K. A. Thomson, and G. J. Smallwood, "Investigation of optical properties of aging soot," Appl. Phys. B, vol. 104, pp. 273-283, 2011.

[19] U. O. Koylu, Y. Xing, and D. E. Rosner, "Fractal morphology analysis of combustion-generated aggregates using angular light scattering and electron microscope images," Langmuir, vol. 11, pp. 4848-4854, 1995. 